CHRISTOPHER J. BALL, The London Hospital Medical College, London E1 2AD

\section{Mental Health Review Tribunals in Bradford}

Sir: The issue of outcome following Mental Health Review Tribunals (MHRTs) has been the subject of recent studies (Wilkinson \& Sharpe, 1993; Saad \& Sashidharan, 1992) but the period from initial application to the hearing itself has received scant attention. We would like to report our study in Bradford. All MHRT applications for sections 2 and 3 from January 1986 to July 1992 were identified. A central register provided data on the fate of applications. Information regarding outcome after successful appeal was extracted from the case-notes and a deliberate self-harm register.

Of 682 patients detained under section 2, 86 (13\%) appealed. This resulted in 70 tribunal hearings. Thirteen patients were discharged by the tribunal from compulsory detention. Within three months, two of these patients deliberately self-poisoned and attended hospital, and six patients required readmission (two compulsorily). Of the 214 patients detained under section 3, $44(21 \%)$ appealed, leading to 25 tribunals. Five patients had their appeal upheld, and none of these were recorded as being readmitted or carrying out acts of self- harm within the follow-up period.

The proportion of patients who appealed is broadly comparable to other studies (Wilkinson \& Sharpe, 1993; Saad \& Sashidharan, 1992). We found two reasons for fallure to proceed to a tribunal hearing after application: withdrawal of application by the patient (four patients on section 2, and two patients on section 3 ) and discharge from the section prior to the tribunal (12 patients on section 2,17 patients on section 3 ). The median time from application to hearing was six days (range $3-8$ ) for section 2 , and 47 days (range 22-112) for section 3.

The lengthy delay between application and hearing in section 3 appeals surprised us and may well be linked with the high rate of discharge by the Registered Medical Officer before the hearing can take place. Further studies are needed to determine whether this is true of the situation nationwide. If so, re-evaluation of procedures should be undertaken.

SAaD, D.A. \& SAShIDARHARAN, S.P. (1992) Mental Health Review Tribunals. Psychiatric Bulletin, 16, 470-472.

WILKINSON, P. \& SHARPE, M. (1993) What happens to patients discharged by Mental Health Tribunals? Psychiatric Bulletin, 17, 337-338.

I.P. MCKENZIE and D. WADDINGTON Leeds General Infirmary, Leeds LS2 9NS

\section{Research by trainees}

Sir: Katona \& Robertson (Psychiatric Bulletin, $1993,17,27-29)$ show that the possession of any publication is associated with shortlisting for a senior registrar interview and advise trainees to "publish ... or be damned". However, many trainees who express an interest in research are actively discouraged, have difficulty finding the time or do not have the appropriate training. (CTC, 1991). Training in particular improves trainees' research performance (Lewis, 1991).

We performed a questionnaire census of psychiatric trainees in the West of Scotland to identify their current research activities and their perceived training needs; 48 replied $(87 \%)$ ). Respondents had been working in psychiatry for a median of 34 months. Seventy-five per cent had sat Part 1 MRCPsych, 14 (29\%) were on training schemes with a research tutor and seven (15\%) with a designated research post. Twenty-two (46\%) recalled undergraduate teaching in research methods, while $17(35 \%)$ had attended post-graduate research lectures, $13(27 \%)$ had attended local research meetings, and two had attended a formal research course. Twenty-two (46\%) reported informal teaching from consultants. Forty-seven (98\%) felt that further training would be useful, preferring active teaching methods. Thirty-one (65\%) had attempted research projects. Twenty-six $(84 \%)$ had experienced difficulties, the most common problem (24 doctors) being finding sufficient time at work.

The most important influence on taking part in research was interest in a clinical topic followed by worry about future promotion. The most important factor influencing choice of project was having a clear research design. The type of research preferred as a next project was clinical research.

The response rate shows this to be an important topic for psychiatric trainees. With less than half of our respondents having received any training in research methods and 98\% feeling they required further teaching, there is clearly a need for structured teaching in this area. Despite this, the majority were taking part in research although most had experienced problems. It has been pointed out that trainees have little time for research as they must acquire clinical skills and pass examinations as well as fulfilling their service requirements. Our results show that most psychiatric trainees are keen to participate in research and, contrary to findings in other specialities (Gaylard \& Lamberty, 1989), do so because of an interest in their work. However, they feel inadequately trained and unsupported in their efforts to receive supervision and time to perform their research. Addressing these issues would improve the likelihood of psychiatric trainees completing good quality research projects. 
CTC (1991) Research by trainees. A report by the Working Party of the Colleglate Trainees' Committee. Psychiatric Bulletin, 16, 239-243.

GAYARD. D.G. \& LAMBERTY, J.M. (1989) The attitudes of junior anaesthetists to research. A survey. Anaesthesia, 44, 681-683.

LEWIS, S. (1991) The right stuff? A prospective controlled trial of trainees' research. Psychiatric Bulletin. 16, 478480.

BRIAN A. KIDD, Tone Vale Hospital, Taunton TA4 1DB; CAMERON STARK, Department of Public Health, Paisley, Scotland, PAI 1DU; and TOM HENDERSON, Parkhead Hospital, Glasgow, Scotland

\section{Issues in the changing services for the psychiatry of learning disabilities}

Sir: In the Yorkshire region consultant psychiatrists in learning disabilities (LD) meet regularly. Our discussions show changes in services for learning disabilities from hospital to community are raising many questions.

Service arrangements. The former Yorkshire 'subregional admission bureaus', with two consultants in each of five extensive areas, have been replaced by districts making their own provision. Now services are fragmented and varied. A few districts still have no consultant. More districts have joint posts in mental illness and LD. These function well, but the consultant/ population ratio is below the $1: 200,000$ recommended by the Royal College.

Consultant sessions. A consultant may operate a 'consultational model' of practice, seeing patients, then returning them to the family doctor and community learning disabilities teams (CLDTs). If a consultant adopts a 'liaison attachment model' and becomes a member of the community team offering continuing care, more sessions are needed.

Case load. A newly appointed consultant may attract many new patients with the implication there is an 'iceberg' of unmet needs. To provide a comprehensive service the consultant needs NHS beds for admissions.

Children. After hospitals ceased admitting longstay children many consultants treated no children. Now children with LD and "challenging behaviour' come to CLDTs. They may be helped by the consultant in LD in collaboration with paediatricians and child psychiatrists.

Follow-up of discharges. Some residents in community units have long histories of mental disturbance. These may involve frequent and time-consuming visits from the consultant. Junior staff, medical GP clinical assistants can contribute to this care.
Medical audit. A small number of regional consultants offers scope for regional and subregional audit of referrals, waiting lists and times, case loads, records, diagnoses, mortality, challenging behaviours, epilepsy, psychiatric medication. treatment and follow-up in the community.

The meetings of the Yorkshire consultants in LD provide a forum for discussion of questions members would otherwise face in isolation. No doubt these topics arise across the country. The recognition of issues is a first step to their solution.

Douglas A. Spencer, Meanwood Park Hospital, Leeds LS6 4QB

\section{Psychiatrists' hobbies}

Sir: I have audited the hobbies of psychiatrists, using Psychiatric Bulletin obituaries for the years 1991 and 1992 as the data source.

Of the obituaries of 46 psychiatrists listed, $26 \%$ were described as "devoted family person". and 19\% with no mention of interests outside psychiatric practice. Many had multiple hobbies: $19 \%$ had two, $8 \%$ three, $8 \%$ four, and $2 \%$ more.

The hobbies were literary, including reading, history, languages, poetry, writing $(24 \%)$; music (17\%); theatre and art (11\%); sports, including mountaineering, rugby, flying, golf, cricket, walking, skiing (10\%); community affairs, travel $(8 \%)$; gardening $(6 \%)$; religious interests $(6 \%)$; fishing (4\%); wine and cooking $(4 \%)$; painting $(2 \%)$; bridge $(2 \%)$; antiques $(2 \%)$. Others were house repairing (one case), engineering (one), horology (one), vintage cars (two), ecology (two), philosophy (one), archaeology (two), and politics (one).

In auditing doctors' hobbies, (Davis, 1993) found that $18 \%$ were literary, $15 \%$ music, none for theatre and art, one case of philosophy, and none for politics in a sample of 404 .

What makes psychiatrists keener on literature and arts? Is it their love of humanitarian studies which brought them to psychiatry or is it psychiatry which made them more interested in humanities? Can we see any hint in the early formative years at medical college which would foretell future specialisation? Can these interests form grounds for encouraging early conscious awareness of job cholce?

By virtue of their work, psychiatrists are interested in humanity and humanities, but can specialisation be linked with personality profiles?

DAvs, A. (1993) Doctors' hobbies. British Medical Journal, 307, 244.

G.K. GAD, Ormskirk \& District General Hospital, Ormskirk L39 2AZ 